\title{
SWITCH in Birmingham, UK: experimental investigation of the ecological and hydrological performance of extensive green roofs
}

\author{
Adam J. Bates • Rae Mackay • Richard B. Greswell • \\ Jon P. Sadler
}

Published online: 5 November 2009

(C) Springer Science+Business Media B.V. 2009

\begin{abstract}
This paper summarises research based in the city of Birmingham, UK, into the ecological and hydrological performance of extensive green roofs designed to act as mitigation for the loss of brownfield habitat. It focuses particularly on possible tradeoffs between design elements that maximise biodiversity potential, and design elements that maximise rainfall run-off management potential.
\end{abstract}

Keywords Brown roof - Design trade-off . Eco-roof · Integrated urban water management · Rooftop garden · Urban ecology

\section{Introduction}

SWITCH in Birmingham (UK) is exploring a number of key technical challenges for the city through a range of experimental research projects. As well as the experimental activities, demonstrations are being carried out of specific concepts of potential benefit for integrated urban water management (see www.switch birmingham.wordpress.com). Three experimental test

A. J. Bates $(\bowtie) \cdot$ R. Mackay · R. B. Greswell ·

J. P. Sadler

School of Geography Earth and Environmental Sciences,

University of Birmingham, Birmingham, UK

e-mail: a.j.bates@bham.ac.uk sites have been adapted or constructed to investigate aspects of urban groundwater pollution and its attenuation, viral contamination risks to groundwaters, and the control of flood risk. New simulation and decision support tools are also being researched and developed. All activities are designed to provide guidance on the potential short and long-term impacts of new technologies and systems for urban water management. They are designed to be usable by the network of city stakeholders who share an interest in the long-term future of sustainable management of Birmingham's water systems, and make up the SWITCH supported Birmingham Learning Alliance. They will also have wider relevance for other Learning Alliances in the environmentally and culturally diverse cities forming the SWITCH global Learning Alliance (see van der Steen and Howe 2009). The goal is to provide new knowledge that can inform a clear long-term vision for more integrated and sustainable urban water management.

In the first of the SWITCH Monitor articles van der Steen and Howe (2009) outlined the hypothesis that design and management initiatives encompassing the entire urban water system will provide more sustainable future solutions than initiatives aimed at optimising separate elements of the system in isolation. This idea can be extended further by adding that an important aspect of all SWITCH research is the implicit recognition that developments in water management cannot be isolated from wider sustainable development goals. Wherever possible, synergies 
between different aspects of environmental and social well-being in the city should be exploited. In this paper, this concept is illustrated using the example of green roofs (a roof covered in a growth medium with plants growing on it) in Birmingham.

\section{Green roof research in Birmingham}

\subsection{Background}

New approaches for working towards urban ecological sustainability using green roofs provided the focal point for our preliminary thinking around the design of the research theme for SWITCH. Research into the design of ecologically sustainable green roofs that are suitable for conditions in Birmingham and elsewhere provided the core aim of the project. The research aims also recognised that such roofs should contribute to urban water sustainability and more widely to urban environmental sustainability.

Currently, post-industrial urban demolition sites (brownfields) in areas of the UK are under considerable development pressure (Harrison and Davies 2002) despite their importance as centres of biodiversity and habitat for a number of rare species (Donovan et al. 2005; Small et al. 2003). True ecological sustainability should at least compensate for habitat lost with habitat of a similar type (Donovan et al. 2005), therefore it was decided to research green roof designs that mitigate for the loss of brownfield habitat on the ground. The idea of redeveloping a site whilst maintaining its ecological value is clearly attractive to both developers and conservationists alike; but, is it really achievable? Can designs relevant to ecological sustainability also contribute to water and environmental sustainability?

Green roofs have been shown to provide a range of potential environmental benefits including: improved building thermal performance, urban cooling, removal of air pollution, and reduced storm-water runoff (Mentens et al. 2006; Oberndorfer et al. 2007; Yang et al. 2008). Understanding this full range of environmental benefits requires expertise in a variety of disciplines, and the different benefits are difficult to assess simultaneously. Not surprisingly, there has therefore been a tendency for individual environmental benefits to be researched in isolation, and a lack of focus on issues surrounding environmental trade-offs associated with different green roof designs (but see Simmons et al. 2008). Green roof designs to replicate brownfield and similar habitats (Brenneisen 2006; Kadas 2006), hereafter referred to as brown roofs, are no exception. Although a significant amount is known about the best ways to maximise their ecological benefits, very little is known about the relative strengths of the other environmental benefits of brown roofs. Our research has investigated one of the trade-offs of major relevance to meeting SWITCH objectives: are green roof designs that mitigate for the loss of brownfield habitat also useful as tools for stormwater management? Can roof designs be achieved that meet both objectives and are they architecturally acceptable both for existing roof renewal and for new build?

\subsection{Research approach}

Previous knowledge gathered from research on the ecology of brownfields (Donovan et al. 2005; Small et al. 2003) and brown roofs (Brenneisen 2006; Kadas 2006) allowed us to outline five basic elements that a well-designed brown roof should include: (1) low nutrient levels in the growth substrate in order to prevent dominance by a few highly competitive plant species; (2) diverse substrate types and depths to provide many microhabitats for a diverse range of species; (3) areas of bare, or sparsely vegetated ground that are necessary microhabitats for a range of species associated with brownfields; (4) areas of coarse sediment to provide cover for invertebrates; and (5) disturbance refugia that provide protection during the severe weather conditions often encountered during extended dry periods or the winter (e.g. dead wood, large stones, and areas of deep substrate). We used these criteria in the design of two complementary research approaches: (a) an experimental assessment of the suitability of different recycled aggregates at a University of Birmingham (UoB) based brown roof test site, and (b) the study of two larger-scale SWITCH demonstration brown roofs at sites in the city.

\subsubsection{The University of Birmingham brown roof test site}

The university test site comprises $35,3 \mathrm{~m}^{2}$ brown roof mesocosms that are $10 \mathrm{~cm}$-deep. There are five 
replicates of each of seven different mixes of recycled aggregate seeded with a wildflower seed mix. Aggregates used in the study were sourced locally, and were considered 'waste' aggregates in the UK before the recent establishment of landfill taxes and aggregate levies. The mesocosms were established in May 2007 (Fig. 1) and the development of plant and invertebrate assemblages on the plots has been, and continues to be, intensively studied. In order to explore possible trade-offs between the ecological and hydrological benefits of the different substrate types, the hydrological performance was measured at the same time for two of the aggregate mixes.

\subsubsection{The demonstration brown roofs}

The two demonstration roofs were installed in the late summer of 2007 on the Birmingham International Convention Centre (ICC), and the Birmingham Volunteer Service Council (BVSC) buildings. Their design and installation was the result of collaboration between a range of organisations including local government, wildlife and sustainable development charities, and business. They fulfilled a dual function within the SWITCH project: (1) to act as working examples of brown roofs that can allow the public to appreciate first hand the design and aesthetics of brown roofs; and (2) to provide macro-scale brown roof research sites where the wider applicability of ecological research findings at the meso-scale could be tested.

Both roofs were designed to provide a wide range of microhabitats to encourage a high diversity of species. The substrates dominantly comprise bimodal sediment distributions that provide ground-dwelling invertebrates with fine sediments to burrow in and coarse sediments to hide under, and have additional features that allow shelter for invertebrates from adverse weather conditions (Figs. 1,2). The SWITCH Birmingham Learning Alliance web page (www. switchbirmingham.wordpress.com) allows the public

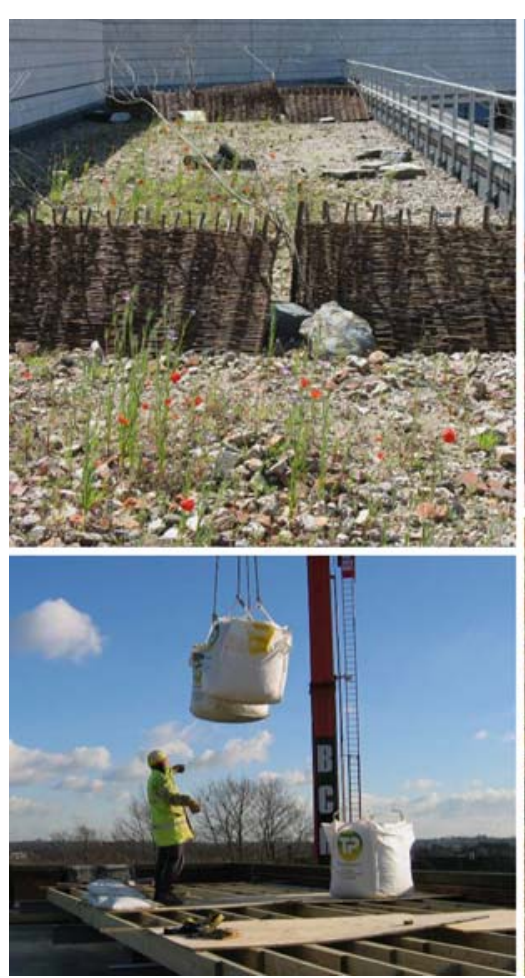

Fig. 1 The construction and development of the UoB brown roof test site and the ICC demonstration brown roof (top left a section of the ICC site, bottom left construction of the UoB site,

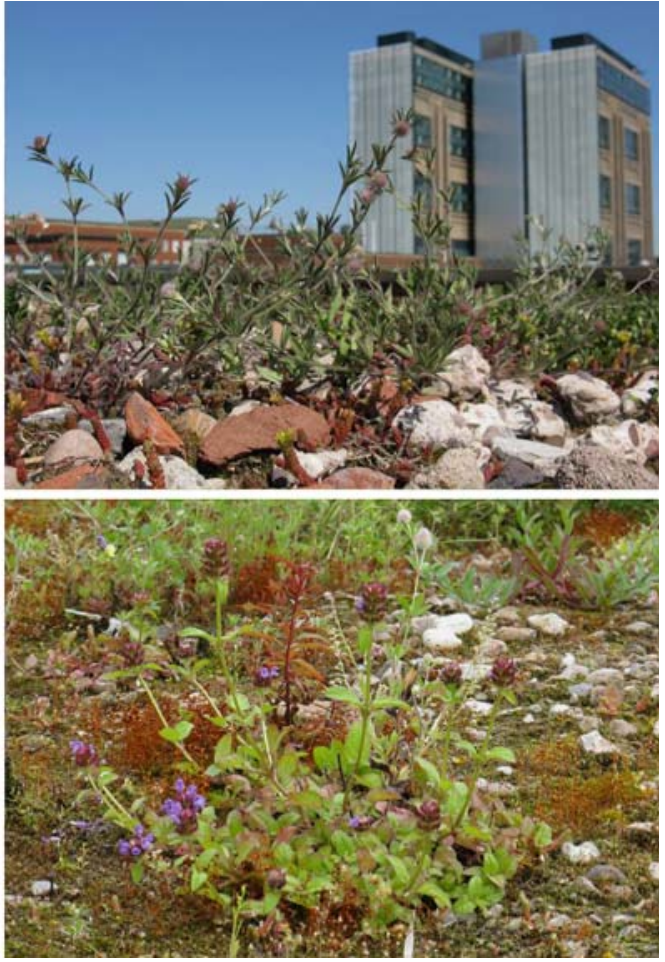

top right Trifolium arvense $\mathrm{L}$. on the $\mathrm{UoB}$ site, bottom left Prunella vulgaris L. on the ICC site) 


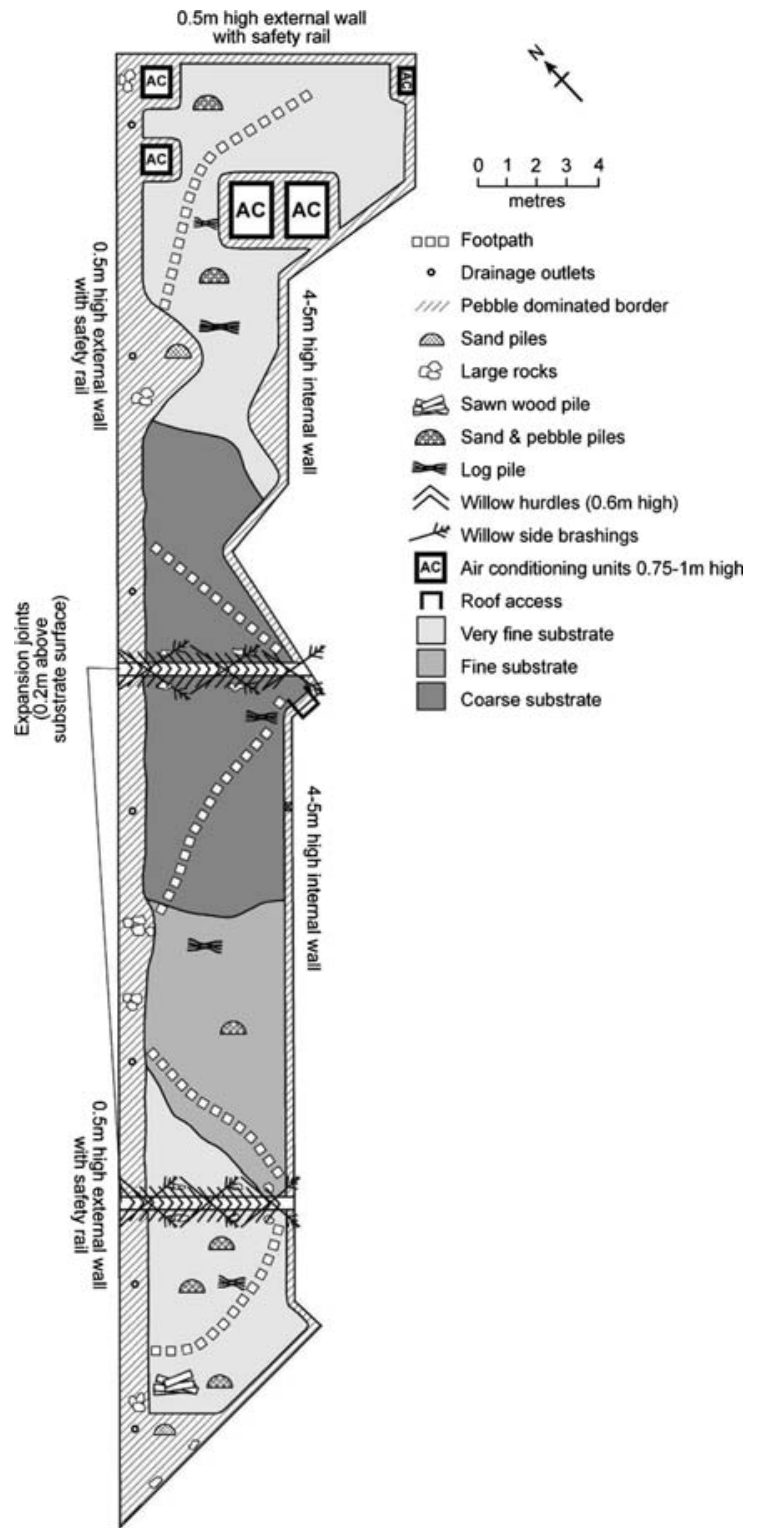

Fig. 2 The design of the ICC demonstration brown roof illustrating a wide range of different microhabitat types

to view details of the roof design, lists plant, invertebrate, and bird species found on the roofs, and shows photographs of the roofs at different seasons and stages of development. Several roof tours have been organised that have allowed architects, chartered surveyors, quantity surveyors, council workers, business representatives, environmental consultants, and members of the general public to gain a better understanding of the structure and environmental benefits of brown roofs.

\subsection{Identification of design trade-offs and future direction}

The ecological communities of green roofs are dynamic and take a long time to stabilise (Dunnett et al. 2008), and the study sites have not yet done so. At this point it is only possible to make broad conclusions until future results and related publications produce more specific findings. However, from existing results and information from published and grey literature, it is certainly possible to provide a first assessment of the general hydrological, ecological, and design performance of the brown roofs (Table 1). Table 1 also specifically assesses the relative performance of the brown roofs against a typical 'off-the-shelf' $8-10 \mathrm{~cm}$ deep, Sedum-based green roof with a designed lightweight, high porosity growth substrate (e.g. expanded clay).

The fiscal and environmental costs of using brown roof aggregates is low because materials are sourced locally and materials are recycled from building demolition or produced as by-products of industrial processes. However, these aggregates are heavy and typically have a low water retention, which increases loading on roof structures and means they have a relatively limited capacity to store water. This means that their hydrological performance is typically poor, even compared to a fairly thin extensive Sedum roof. While retardation and reduction of drainage flows from low intensity storms does arise, events that are liable to cause flooding are not significantly attenuated. While flooding control using the basic designs is impractical, there are still potential benefits in terms of the downstream regulation of stream flows if sufficient roof area is covered in an urban catchment (see also Mentens et al. 2006). Ecologically, the first indications from this and other research (Brenneisen 2006; Kadas 2006), are that brown roofs are less ecologically productive, but more ecologically diverse than 'off-the-shelf' Sedum-based products. Whether they can provide reasonable mitigation for the loss of ground-based habitats is still not clear (Table 1).

The research so far summarised has been heavily steered by the existing situation in the City of Birmingham; but the SWITCH visions for the 'city of the future' will require the exploration of a variety of future scenarios. As the research progresses, investigations will upscale to the construction of regional 
Table 1 First assessment of the performance of brown roofs relative to green roofs generally, and specifically to an 'off-the-shelf' Sedum based green roof with a designed substrate

\begin{tabular}{|c|c|c|c|c|}
\hline Feature & & $\begin{array}{l}\text { Overall brown } \\
\text { roof performance }\end{array}$ & $\begin{array}{l}\text { Relative performance } \\
\text { against Sedum roof }\end{array}$ & $\begin{array}{l}\text { Level of } \\
\text { understanding }\end{array}$ \\
\hline Cost & & Fair & Similar & Good \\
\hline Loading & & Fair & Lower & Good \\
\hline Transport \& energy investment & & Fair & Better & Fair \\
\hline \multirow[t]{3}{*}{ Aesthetics } & - general & Fair & Lower & Fair \\
\hline & - repeatability & Poor & Lower & Fair \\
\hline & - seasonality & Poor & Lower & Fair \\
\hline \multirow[t]{2}{*}{ Ecological productivity } & - relative to green roofs & Poor & Lower & Fair \\
\hline & - relative to ground-based & Poor & - & Poor \\
\hline \multirow[t]{2}{*}{ Ecological diversity } & - relative to green roofs & Good & Better & Fair \\
\hline & - relative to ground-based & Fair & - & Fair \\
\hline Hydrological performance & & Poor & Lower & Fair \\
\hline
\end{tabular}

Note: The hydrological performance of brown roofs can be substantially improved through substrate depth increases and texture modifications but at the expense of energy investment and loading

scoping tools to test and model the efficacy of different brown roof designs, and our knowledge will grow as the brown roofs mature. This will allow us to address questions such as: "Can shallow extensive green roofs installed on all flat roofs in Birmingham make a significant contribution to storm-water management?" to "What depth would green roofs need to be to make a significant contribution to storm-water management in the city of 2050?". This shift in focus from 'what can be done', to 'what needs to be done' embodies the SWITCH paradigm shift in approaches to urban water management.

\section{Conclusions}

The study roofs are providing initial indications of the benefits of brown roofs for ecological and hydrological sustainability. Ecological improvements compared to other green roof designs are apparent, but the hydrological benefits of the current designs are generally limited. Revision of the designs to support their hydrological function are possible through the enhancement of the water retention capacity of the substrate. However, the ecological impacts are, as yet, unclear and the economic and environmental benefits will need to be addressed. Work is ongoing on the expansion of the research to include assessments of the potential for future uptake of these roofs at a city scale and the adaptation of these roofs to other climate types and urban environments.

Acknowledgments The design, construction and research on the ICC and BVSC brown roofs was funded in partnership with SITA Trust from landfill tax, the Birmingham Environment Partnership, Advantage West Midlands and the Environment Agency. The project was delivered by a Sustainable Eastside and Groundwork Birmingham and Solihull led design partnership that included the Birmingham and Black Country Wildlife Trust, Livingroofs.org, Shire Consulting, the NEC Group, the BVSC, and Birmingham City Council Urban Design. We thank Rossa Donovan for his early contributions to the project, Rosemary Coyne for her work on the design proposal, and Dusty Gedge, Emorsgate wild seed company, and Permanite Engineered Roofing Systems for initial advice on the design of green roofs. The work of the wider Birmingham Learning Alliance, of which many of those mentioned above are members, facilitated by Jennifer Chlebek at Arup, Solihull has provided a focal point for wide ranging discussions around the project.

\section{References}

Brenneisen S (2006) Space for urban wildlife: designing green roofs as habitats in Switzerland. Urban Habitats 4:27-36

Donovan R, Sadler J, Bryson J (2005) Urban biodiversity and sustainable development. Eng Sustain 2005:105-114

Dunnett N, Nagase A, Hallam A (2008) The dynamics of planted and colonising species on a green roof over six growing seasons 2001-2006: influence of substrate depth. Urban Ecosyst 11:373-384

Harrison C, Davies G (2002) Conserving biodiversity that matters: practitioners' perspectives on brownfield 
development and urban nature conservation in London. J Environ Manage 65:95-108

Kadas G (2006) Rare invertebrates colonizing green roofs in London. Urdan Habitats 4:66-86

Mentens J, Raes D, Hermy M (2006) Green roofs as a tool for solving the rainwater runoff problem in the urbanized $21 \mathrm{st}$ century? Lands Urban Plan 77:217-226

Oberndorfer E, Lundholm J, Bass B, Coffman RR, Doshi H, Dunnett N, Gaffin S, Kohler M, Liu KKY, Rowe DB (2007) Green roofs as urban ecosystems: ecological structures, functions, and services. Bioscience 57:823-833

Simmons MT, Gardiner B, Windhager S, Tinsley J (2008) Green roofs are not created equal: the hydrologic and thermal performance of six different extensive green roofs and reflective and non-reflective roofs in a sub-tropical climate. Urban Ecosyst 11:339-348

Small EC, Sadler JP, Telfer MG (2003) Carabid beetle assemblages on urban derelict sites in Birmingham, UK. J Insect Conserv 6:233-246

van der Steen P, Howe C (2009) Managing water in the city of the future; strategic planning and science. Rev Environ Sci Biotechnol 8:115-120

Yang J, Yu Q, Gong P (2008) Quantifying air pollution removal by green roofs in Chicago. Atmos Environ 42:7266-7273 